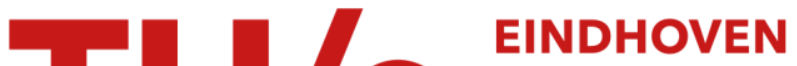 UNIVERSITY OF TECHNOLOGY
}

\section{Temperature-dependent near-field imaging of delocalized and localized excitons in single quantum wires}

\section{Citation for published version (APA):}

Intonti, F., Emiliani, V., Lienau, C., Elsaesser, T., Nötzel, R., \& Ploog, K. H. (2001). Temperature-dependent near-field imaging of delocalized and localized excitons in single quantum wires. In Quantum Electronics and Laser Science Conference, 2001. QELS '01. Technical Digest. Summaries of Papers Presented at the (pp. 2223). Optical Society of America (OSA). https://doi.org/10.1109/QELS.2001.961797

DOI:

10.1109/QELS.2001.961797

Document status and date:

Published: 01/01/2001

\section{Document Version:}

Publisher's PDF, also known as Version of Record (includes final page, issue and volume numbers)

\section{Please check the document version of this publication:}

- A submitted manuscript is the version of the article upon submission and before peer-review. There can be important differences between the submitted version and the official published version of record. People interested in the research are advised to contact the author for the final version of the publication, or visit the $\mathrm{DOI}$ to the publisher's website.

- The final author version and the galley proof are versions of the publication after peer review.

- The final published version features the final layout of the paper including the volume, issue and page numbers.

Link to publication

\section{General rights}

Copyright and moral rights for the publications made accessible in the public portal are retained by the authors and/or other copyright owners and it is a condition of accessing publications that users recognise and abide by the legal requirements associated with these rights.

- Users may download and print one copy of any publication from the public portal for the purpose of private study or research.

- You may not further distribute the material or use it for any profit-making activity or commercial gain

- You may freely distribute the URL identifying the publication in the public portal.

If the publication is distributed under the terms of Article 25fa of the Dutch Copyright Act, indicated by the "Taverne" license above, please follow below link for the End User Agreement:

www.tue.nl/taverne

Take down policy

If you believe that this document breaches copyright please contact us at:

openaccess@tue.nl

providing details and we will investigate your claim. 
(a) as grown

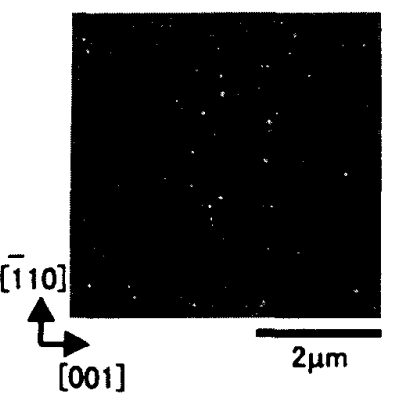

(c) $\mathrm{T}=560^{\circ} \mathrm{C}, 10 \mathrm{~min}$.

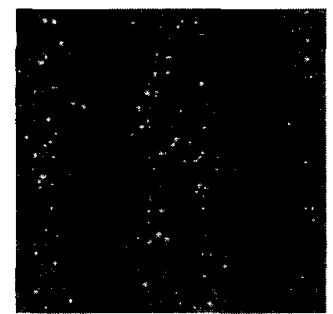

(b) $\mathrm{T}=490^{\circ} \mathrm{C}, 10 \mathrm{~min}$

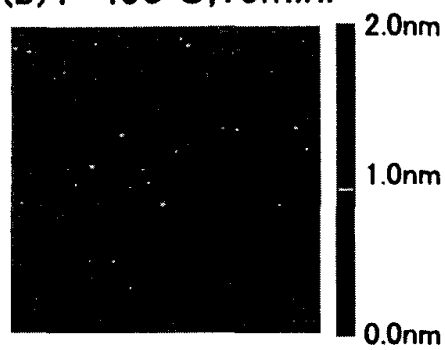

(d) $\mathrm{T}=600^{\circ} \mathrm{C}, 10 \mathrm{~min}$

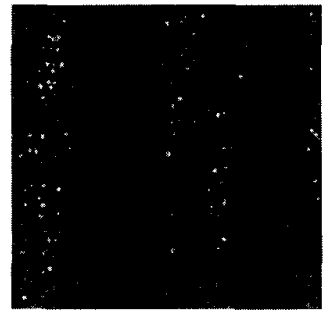

QMF5 Fig. 2. AFM images of the surfaces of 5-nm (110) GaAs layers grown on the cleaved edge at the same growth conditions and subsequently annealed at various substrate temperatures for $10 \mathrm{~min}$. The observation area of the images is $5 \mu \mathrm{m} \times 5 \mu \mathrm{m}$.

West, and B.S. Dennis, "Metamorphosis of a quantum wire into quantum dots," Nature 390, 54-57 (1997).

11:30 am

Temperature-dependent near-fleld Imaging of delocalized and localized excitons in single quantum wires

Francesca Intonti, Valentina Emiliani,

Christoph Lienau, Thomas Elsaesser, Max-BornInstitut für Nichtlineare Optik und

Kurzzeitspektroskopie D-12489 Berlin, Germany;

* permanent address: INFM, LENS, 1-50125,

Firenze; Email: intonti@mbi-berlin.de

Richard Nötzel and Klaus H. Ploog, Paul-DrudeInstitut für Festkörperelektronik, D-10117 Berlin, Germany

Recent microphotoluminescence studies ${ }^{1,2}$ have shown that the low-temperature emission spectra of semiconductor quantum wires are dominated by localized, quasi-zero-dimensional, excitons. This implies that both the optical and transport properties of such quasi-one-dimensional (Q1D) nanostructures are similar to that of a chain of quantum dots. It also hinders the observation of some truly one-dimensional quantum effects, such as the ballistic or diffusive one-dimensional exciton transport, expected in nanostructures containing Q1D excitons that are delocalized over mesoscopic length scales.

In this paper, we present the first experimental evidence for such delocalized excitons in a single quantum wire. ${ }^{3}$ A novel coupled QWR-Dot nanostructure ${ }^{4}$ is studied by low temperature near-field photoluminescence (PL) spectroscopy. Near-field spectra are recorded at $10 \mathrm{~K}$ with combined spatial/spectral resolution of $150 \mathrm{~nm}$ and $0.1 \mathrm{meV}$, respectively. Spectra (Fig. 1b) taken in the QWR region of the structure contain an intense set of energetically sharp emission peaks (e.g., at $1.6695 \mathrm{eV}$ ). Two-dimensional near-field images (Fig. 1c) show that these emission spikes stem from single localized excitons.

In addition to the sharp spikes, the PL spectrum (Fig. 1b) shows a broad, less intense background component. At the low energy side of the continuum, the PL spatial distribution reveals the existence of regions with a larger average extension of 400-600 nm in diameter (Fig. Id). For de- tection energies in the high energy part of the emission band, a completely different situation appears. Here, the two-dimensional images (Fig. le) indicate an uniform PL distribution delocalized along the $\mathrm{QWR}$ axis on a length scale of more than $2 \mu \mathrm{m}$. Such delocalized PL components are observed for a broad range of detection energies (circles in Fig. 1b).

The experimental observation of delocalized Q1D excitons is strongly supported by theoretical simulations of the effects of monolayer thickness fluctuations on the excitonic QWR eigenstates. The calculations suggest that delocalized states in a disordered QWR structure give rise to a broad distribution of energetically densely spaced weak resonances in the optical spectra (about 10 states $\left./\left(\mu \mathrm{m}^{*} \mathrm{meV}\right)\right)$. The linewidth of these individual resonances is broader than their energy separation and a broad structureless band appears in absorption and-for sufficient thermal population-also in the PL spectra.

Additional experimental evidence for the one-dimensional character of the investigated quantum wire is gained from a study of the exciton-acoustic phonon coupling in our QWR. Temperature-dependent measurements of the PL linewidths of single localized excitons (Fig. 2) evidence a strong, more than two-fold enhancement of coupling to phonons compared to that in the embedding QW layer. Such an enhancement is expected for QWRs with a high density of delocalized Q1D eigenstates and in agreement with our theoretical calculations.

In conclusion, we have spectrally and spatially resolved the emission of localized and delocalized excitons in a novel QWR nanostructure. We observe that the one-dimensional confinement of excitons give rise to a strong enhancement of the exciton-acoustic-phonon coupling.

1. J. Hasen et al., Nature 390, 54 (1997).

2. F. Vouilloz et al., Solid State Comm. 108, 945 (1998).

3. F. Intonti et al., Phys. Rev. B, in press.

4. J. Fricke et al., J. Appl. Phys. 85, 3576 (1999).
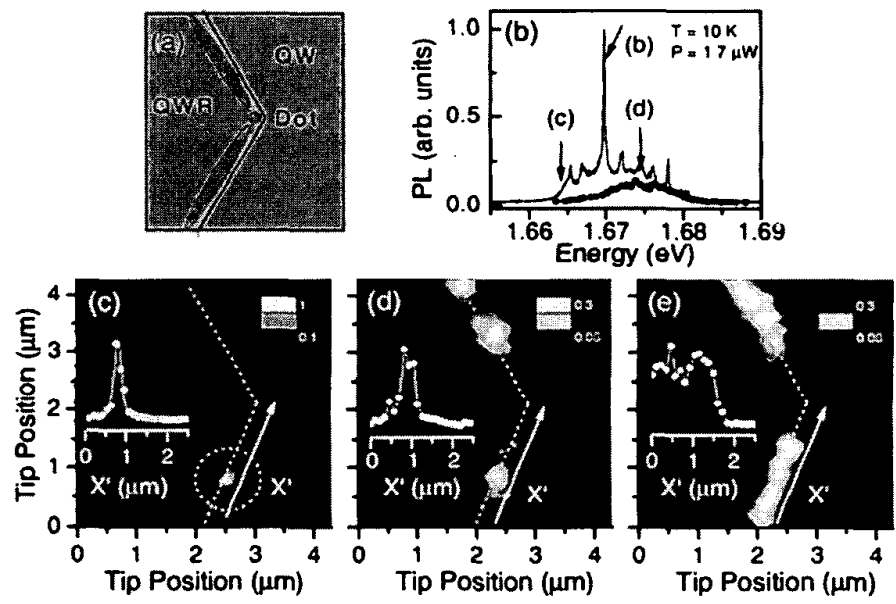

QMF6 Fig. 1. (a) Schematic of the QWR-Dot nanostructure. (b) Near-field PL spectrum of the QWR taken at $10 \mathrm{~K}$ at a fixed spatial position. (circles) Spectral distribution of the spatially delocalized PL component. (c)-(e) Two-dimensional near-field PL images recorded at (c) $1.6698 \mathrm{eV}$ (localized exciton), (d) $1.6632 \mathrm{eV}$, and (e) $1.674 \mathrm{eV}$ (delocalized exciton). The insets give cross-sections along the QWR axis X. 


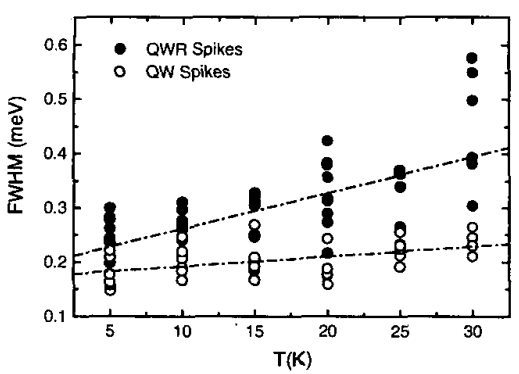

QMF6 Fig. 2. Temperature-dependent linewidth of the emission spikes from single localized excitons in the quantum well (open circles) and quantum wire (closed circles) region of the sample.

QMF7

11:45 am

Resonant Stokes and anti-Stokes luminescence of GaAs/AIGaAs quantum dots on a (411)A GaAs surface

C. Watatani, K. Edamatsu*, T. Itoh, S. Shimomura and S. Hiyamizu, Division of Materials Physics, Graduate School of Engineering Science, Osaka University, Toyonaka, 560-8531, Japan;Email*:edu@.mp.es.osaka-u.ac.jp

Recent studies of semiconductor quantum dots (QDs) using optical micro-probing techniques have revealed many unique and interesting properties of an individual QD, such as sharp homogeneous linewidth ${ }^{1,2}$ luminescence intermittency, ${ }^{3,4}$ optical nonlinearity, ${ }^{5}$ and nonclassical light emission. ${ }^{6}$ We have investigated the $\mu$-photoluminescence $(\mu-\mathrm{PL})$ and excitation ( $\mu$-PLE) spectra of GaAs/AlGaAs QDs grown on a (411)A GaAs surface. Under resonant excitation of the dot, we have observed several PL lines corresponding to discrete energy levels of the dot. Surprisingly, we found that the PL lines appear not only on the Stokes side but also on the anti-Stokes side even at low temperature.

The GaAs QDs used in this study are based on a $\mathrm{GaAs} / \mathrm{Al}_{0.3} \mathrm{Ga}_{0.7} \mathrm{As}$ quantum well (QW) grown on a (411)A GaAs surface. ${ }^{8} \mathrm{~A}$ small number of QDs are included in a triangular-pyramidal structure formed on the GaAs surface. We performed $\mu$-PL and $\mu$-PLE measurements of the single pyramidal structure at $3.8 \mathrm{~K}$.

The $\mu$-PL spectrum observed from the single pyramidal structure is shown in Fig. 1(c). The $\mu$ PLE spectra detected at four luminescence lines (\#1 to \#4 in Fig. 1(c)) are shown in Figs. 1(a) and (b). The PLE spectra have several sharp peaks reflecting the discrete energy levels of the $\mathrm{QD}$. Close similarity between the PLE spectra for \#1 and \#4, and for $\# 2$ and $\# 3$, suggests that the luminescence $\# 1$ and $\# 4$ originates from an identical dot, and \#2 and \#3 from another dot in a pyramid. Furthermore, it is noteworthy that the lines \#4 and \#3 have sharp anti-Stokes resonance at the lines \#1 and $\# 2$, respectively.

Figure 2 shows the PL spectra for various excitation power under resonant excitation at the downward arrow, which corresponds to the line $\# 4$ in Fig. 1(c). One can clearly see that the PL lines appear on both the Stokes and anti-Stokes sides. The energy separation of the anti-Stokes PL ranges over more than $6 \mathrm{meV}$. Because the spectra were taken at low temperature $(3.8 \mathrm{~K})$, the anti-

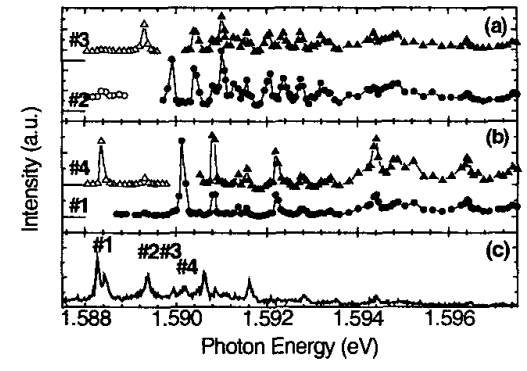

QMF7 Fig. 1. $\mu$-PLE (a,b) and $\mu$-PL (c) spectra of the GaAs QDs at 3.8K. The $\mu$-PLE spectra were detected at the four sharp lines $(\# 1 \sim \# 4)$ indicated in the $\mu$-PL spectrum.

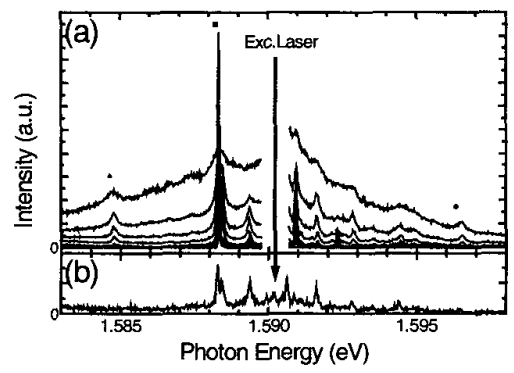

QMF7 Fig. 2. (a) $\mu$-PL spectra under the resonant excitation at $1.5902 \mathrm{eV}$ (indicated by the downward arrow). The excitation power $\left(\mathrm{P}_{\text {exc }}\right)$ varied from 11 to $5500 \mathrm{~W} / \mathrm{cm}^{2}$ from the lower to upper curves. (b) $\mu$-PL spectrum under excitation at $1.687 \mathrm{eV}, P_{\text {exc }}=5.5 \mathrm{~W} / \mathrm{cm}^{2}$.

Stokes PL cannot originate from thermal excitation. To discuss the origin of the PL lines, we have analyzed the excitation power dependence of the PL line intensities. From the analysis, we found that the anti-Stokes PL lines indicated by a filled circle in Fig. 2 arises when at least two excitons are created in the QD. Thus, the anti-Stokes PL line is supposed to be caused by Auger excitation of the dots, which often results in the luminescence intermittency and photo darkening effects. ${ }^{3,4}$ On the other hand, since the Stokes PL line (square in Fig. 2) appears when one exciton is created in the $Q D$, it is attributed to the recombination of the lowest excitonic state of the QD that is initially excited to the higher state. Furthermore, the PL line (triangle in Fig. 2) that appears under high excitation density arises when two excitons are created in the QD. Thus, this line is attributed to the emission from the biexciton in the QD, the binding energy of which is $3.4 \mathrm{meV}$ in this case. The co-existence of the Auger excitation and the biexciton luminescence in a QD is an interesting and important problem to be discussed.

1. D. Gammon, E.S. Snow, B.V. Shanabrook, D.S. Katzer and D. Park, "Homogeneous Linewidths in the Optical Spectrum of a Single Gallium Arsenide Quantum Dot," Science 273, 87-90 (1996)

2. N.H. Bonadeo, J. Erland, D. Gammon, D. Park, D.S. Katzer and D.G. Steel, "Coherent Optical Control of the Quantum State of a Single Quantum Dot," Science 282, 1473 1476 (1998)

3. M. Nirmal, B.O. Dabbousi, M.G. Bawendi, J.J. Macklin, J.K. Trautman, T.D. Harris, and L.E. Brus, "Fluorescence Intermittency in Single Cadmium Selenide Nanocrystals," Nature 383, 802-804 (1996).

4. Al.L. Efros and M. Rosen, "Random Telegraph Signal in the Photoluminescence Intensity of a Single Auantum Dot," Phys. Rev. Lett. 78, 1110-1113 (1997).

5. N.H. Bonadeo, G. Chen, D. Gammon, D.S. Katzer, D. Park and D.G. Steel, "Nonlinear Nano-Optics: Probing One Exciton at a Time," Phys. Rev. Lett. 81, 2759-2762 (1998).

6. P. Michler, A. Imamoğlu, M.D. Mason, P.J. Carson, G.F. Strouse and S.K. Buratto, "Quantum Correlation among Photons from Single Quantum Dot at Room Temperature," Nature 406, 968-970 (2000).

7. C. Watatani, K. Edamatsu, T. Itoh, $\mathrm{H}$. Hayashi, S. Shimomura and S. Hiyamizu, "Confined multiexciton states of GaAs/AlGaAs quantum dots grown on a (411)A GaAs surface," Phys. Stat. Sol. (b), in press.

8. H. Hayashi, S. Shimomura, and S. Hiyamizu, unpublished.

QMG

\section{Atomic Coherence}

Jeffrey H. Shapiro, MIT, USA, Presider

QMG1.

10:15 am

Entangling an atomlc vapor: Spin squeezing in degenerate and nondegenerate systems,

N. Bigelow, Univ. of Rochester, USA

Summary not available.

QMG2

10:45 am

Optlcal Ramsey-type magnetometer using coherent population trapping

A.V. Taichenachev, A.M. Tumaikin, V.I. Yudin, Novosibirsk State University, 2 Pirogova, Novosibirsk 630090, Russia;

Email: llf@admin.nsu.ru

By now there have been proposed and partly realized in experiments several optical schemes for the precise measurement of a magnetic field. Among them the most promising methods are based on atomic coherence (first proposed by Scully and Fleischhauer in 1992). In one of optical schemes the interaction with spatially separated fields was used, ${ }^{1}$ following to the Ramsey method.

We propose a new variant of magnetometer, where the advantages of the Ramsey method are combined with the high-contrast detection provided by the coherent population trapping effect. In our scheme for the measurement of arbitrary directed magnetic field $\mathbf{B}$ a cell with atomic vapor is used, see in Fig. 1. These atoms with optical transition $1 \rightarrow 1$ are being under the resonant interaction with a pulsed polarized laser field. The 